\title{
Avaliação da motricidade ampla e fina na Síndrome de Williams: Relato de caso
}

\author{
Marcela Melo Almeida ${ }^{1}$ \\ Cibelle Kayenne Martins Roberto Formiga ${ }^{2}$ \\ ${ }^{1}$ Especialista em Fisioterapia em Pediatria e Neonatologia, Universidade São Marcos, \\ Centro de Estudos Avançados e Formação Integrada (CEAFI), Goiânia, GO, Brasil \\ ${ }^{2}$ Fisioterapeuta, Professora do Curso de Fisioterapia da Universidade Estadual de Goiás, \\ Goiânia, GO, Brasil
}

\begin{abstract}
Resumo: O presente estudo teve como objetivo analisar os achados da motricidade ampla e fina de uma criança de 8 anos de idade portador da Síndrome de Williams. Foram coletados dados biológicos da criança e da mãe durante a gestação e história pré, peri e pós-natal da criança e suas condições clínicas. O desenvolvimento motor amplo e fino foi avaliado pelo Inventário Portage Operacionalizado. Os resultados demonstraram que a criança revelou maior dificuldade na motricidade fina em relação à ampla, apresentando dificuldades na escrita, em manipular objetos que necessite fazer movimento de pronação e supinação e dificuldade no movimento de pinça.
\end{abstract}

Palavras-chave: Síndrome de Williams. Motricidade ampla e Fina. Desenvolvimento motor.

\section{Findings of the gross and fine motor in the Syndrome William Case: Case Report}

\begin{abstract}
This study aimed to analyze the findings of motor and fine of an 8 years old holder of Williams Syndrome. Data were collected biological child and mother during pregnancy and history of pre, peri and postnatal child and their clinical conditions. The development and fine motor function was assessed by Portage Guide. The results showed that children showed greater difficulty with fine motor skills in relation to gross skills, having difficulty in writing, to manipulate objects that need to make movement of pronation and supination and difficulty in of the pincer movement.
\end{abstract}

Key Words: Williams Syndrome. Gross and fine motricity. Motor Development.

\section{Introdução}

A Síndrome de Williams ou Síndrome de Williams-Beuren (SWB) caracteriza-se por múltiplas anomalias associadas a retardo mental. Foi descrita pela primeira vez em 1961 por um médico neozelandês, Dr. J. C. P.Williams, quando verificou que um grupo de pacientes pediátricos possuía sintomas parecidos, problemas cardiovasculares, rostos com características semelhantes, atraso mental moderado, dificuldade para ler, escrever e efetuar operações matemáticas (ROSSI et al., 2006).

A síndrome de Williams é uma rara desordem genética freqüentemente não diagnosticada. Não é transmitida geneticamente e não apresenta causas ambientais, médicas ou influência de fatores psicossociais. Exerce impacto em diversas áreas do desenvolvimento, incluindo a cognitiva, comportamental e motor (ARAVENA et al., 2002).

Está Síndrome ocorre em um a cada 7.500 recém nascidos e sua etiologia está associada a uma microdeleção hemizigótica, isto é, a perda de uma das cópias dos genes, localizados na região 7q11.23 (ROSSI et al., 2006) Aproximadamente 20 genes podem estar deletados nesta região cromossômica, dentre os quais se inclui o gene da elastina (ELN). O gene ELN está deletado em aproximadamente 96\% dos casos de SWB, o que justifica a sua investigação para confirmação diagnóstica da SWB (EWART et al, 1993).

Pode ser detectada pela técnica da cito genética molecular, teste de hibridização in situ por fluorescência (Fish) em 90-95\% dos pacientes. O resultado FISH negativo para a deleção do gene ELN não exclui o diagnóstico da SWB, que deve considerar a presença de sinais clínicos típicos da síndrome e a investigação por outras técnicas moleculares mais específicas para identificação de outros genes envolvida (SUGAYAMA, 2000; ROSSI et al., 2006).

A hibridização in situ é uma técnica citogenética que permite a localização de uma seqüência específica de ácido desoxirribonucléico (DNA) numa banda 
cromossômica. Isto pode ser realizado somente se a seqüência clonada de DNA, ou seja, uma sonda estiver disponível. A técnica consiste na hibridização de uma sonda marcada com corantes fluorescentes ou radioativas, para identificar o seu segmento complementar dentro de uma metáfase cromossômica espalhada numa lâmina. O DNA dos cromossomos metafásicos é desnaturado na própria lâmina (daí a técnica ser denominada de in situ), iniciando-se, a seguir a hibridização com a sonda marcada. A sonda é visualizada por fluorescência, no caso da técnica de FISH, ou por filme de raio $X$. Acreditamos que nos pacientes com quadro típico de SWB, o teste de FISH não seria imprescindível, principalmente nos hospitais da rede pública, uma vez que o custo do teste é muito elevado no nosso meio.

A maioria dos trabalhos da literatura refere-se à SWB como uma doença sem predomínio de sexo ou região geográfica. $\mathrm{Na}$ maioria das famílias a ocorrência é esporádica, ou seja, ambos os pais não possui a síndrome. No entanto, existem alguns casos familiais descritos. Em todos eles o diagnóstico do genitor afetado foi feito somente após o diagnóstico da criança afetada. A SWB também foi descrita em gêmeos monozigóticos concordantes e gêmeos dizigóticos discordantes (SUGAYAMA, 2000).

Pode ser considerada como a primeira síndrome onde se descobriu um defeito molecular antes da anormalidade citogenética. Associaram estenose aórtica supra valvular (ESVA) com a lesão do cromossomo 7 , mais precisamente ao gene da elastina mapeado na banda 7q11.23 (EWART et al., 1993).

Os critérios de diagnósticos são características faciais típica dos "duendes" (fronte larga, cristas orbitais sobressaltadas, fendas palpebrais curtas, epicanto, abundância de tecido subcutâneo em torno dos olhos, nariz em sela com sulco nasolabial longo e lábios grossos) associado às seguintes alterações: problemas cardiovasculares, especialmente a estenose aórtica supra valvular ou estenose da artéria pulmonar; dificuldade precoce de alimentação/irritabilidade; dificuldade de aprendizado; baixo desenvolvimento estatural; hipercalcêmica; personalidade excessivamente social; perda ou má oclusão dentária (MACHADO et al., 1998).
$\mathrm{Na}$ idade adulta, a face modifica-se com formato alongado e lábios mais espessos. Cabelos grisalhos e enrugamento da pele podem ocorrer precocemente na idade adulta jovem (MORENO et al., 1982).

A deficiência mental (DM) está presente em todos os pacientes. O coeficiente de inteligência (QI) varia de 41 a 80. Algumas crianças são mais afetadas que outras, porem a maioria encontra-se na faixa de DM leve e moderado (ROSSI et al., 2006). A DM está associada a um perfil cognitivo e lingüístico distinto, caracterizado por dificuldades lingüísticas e déficit visuo-espacial. Algumas crianças podem ainda apresentar distúrbios de comportamento como impulsividade e manifestações artísticas (VICARI, 2004; CARRASCO, 2005).

Em comparação a outros pacientes portadores de DM com QI semelhantes, as crianças com SWB falam com maior fluência, possuem vocabulário mais extenso e são bons conversadores. O grau de compreensão pode ser limitado e o conteúdo do discurso pode ser anormal, com o uso inadequado de frases estereotipadas (SUGAYAMA, 2001).

As deficiências em tarefas não verbais como cognição visuo-espacial, manipulação de números, solução de problemas e planejamento motor tornam-se mais evidentes posteriormente e não melhoram com a idade. As crianças afetadas apresentam dificuldade na compreensão de conceitos matemáticos, temporais, de distância e de velocidade (ROSSI et al., 2006).

As crianças apresentam atraso no aparecimento da linguagem e começam a produzir frases usualmente após os três anos de idade (CARRASCO et al., 2005).

Algumas características de personalidade são particularmente comuns nas crianças com SW: grande sociabilidade; entusiasmo exuberante; sensibilidade com as emoções alheias; sentemse excessivamente á vontade com estranhos; pequeno intervalo de atenção; medo de altura, escadas e superfícies irregulares; preocupação excessiva com determinados assuntos ou objetos (MORENO; LACASSIC, 1982; ANTONELL, 2006).

Observa-se no primeiro ano de vida a hipotonia muscular sendo muito freqüente, levando ao atraso no desenvolvimento motor prejudicando na deambulação andando por volta 
de 21 meses de idade (SUGAYAMA, 2000; GESTÃO et al., 2007).

A limitação à supinação do antebraço com ou sem sinostose rádio-ulnar pode estar presente em 10\% dos pacientes com SWB. A limitação resulta da sinostose é variável, podendo afetar a escrita. A correção cirúrgica está indicada quanto ocorre uma limitação significativa. A fisioterapia pode auxiliar na melhora das contraturas articulares se for iniciada em fase precoce e mantida por período prolongado. Se os pacientes não recebem tratamento, as contraturas agravam-se com a idade (SUGAYAMA, 2000).

A suspeita diagnóstica da SWB é essencialmente clínica baseada nos achados de exame física, já descritos no quadro clínico, e nos exames complementares (SUGAYAMA, 2001).

O objetivo do presente estudo foi analisar os achados da motricidade ampla e fina de um portador de Síndrome de Williams.

\section{Material e Método \\ Participante e local do estudo}

Participou do estudo uma criança com Síndrome de Williams, sexo masculino com 8 anos de idade. A coleta de dados foi realizada na residência da criança.

\section{Aspectos Éticos}

Este estudo foi previsto de acordo com as Diretrizes e Normas Regulamentadoras de Pesquisas envolvendo seres humanos (Resolução 196/1996, do Conselho Nacional de Saúde). O estudo foi aprovado pelo Comitê de Ética em Pesquisa do Hospital Geral de Goiânia, bem como teve autorização da família da criança. Os pais e/ou responsáveis pela criança autorizaram a participação da criança assinando o Termo de Consentimento Livre e Esclarecido.

\section{Materiais e Instrumentos}

Para a realização do registro dos dados coletados foram utilizados os seguintes materiais e instrumentos:

a) Roteiros de anamnese, onde foram anotados dados biológicos da criança e da mãe durante a gestação, além da história pré, peri e pós natal da criança, inclusive em relação às suas condições clínicas, dados da criança como: desenvolvimento motor, idade, escolaridade, dificuldades na escola, lazer que the agrada, dificuldades encontradas nas atividades de vida diária, dificuldades na alimentação, se realiza terapias e quais são elas, qual a queixa principal da mãe em relação a seu filho. b) Ficha de Avaliação do Desenvolvimento Motor do Inventário Portage Operacionalizado (IPO) (WILLIAMS; AIELLO, 2001), onde foi avaliado o desempenho da criança em relação às atividades do desenvolvimento motor amplo e fino.

Os seguintes equipamentos que foram utilizados para a coleta dos dados: mesa para criança escrever, tesoura, apontador, lápis de core, papel, revistas, bola, pula corda, martelo e prego, skate e patine-te, balanço, escorregador, tábuas, escadas, todos os materiais foram manipulados pela pesquisadora e a criança só realizou a tarefa motora solicitada.

\section{Procedimentos}

A criança selecionada foi avaliada e acompanhada uma só vez em sua casa. No dia da avaliação aos pais ou responsáveis foram explicados os objetivos e a relevância dessa pesquisa, além de esclarecimentos de qualquer dúvida sobre a mesma. Sendo que, voluntariamente, participou do estudo somente a criança cujo responsável autorizou a participação do menor por meio da assinatura do Termo de Consentimento Livre e Esclarecido.

Foi realizada uma entrevista com a mãe da criança para coletar dados de como foi sua gestação, se teve complicações durante ou após a gestação, como foi o parto, se o bebê nasceu em bom estado geral (Apgar, peso, estatura, tempo de internação), como foi o desenvolvimento motor da criança, a idade, escolaridade, dificuldades encontradas, queixas encontradas, com quantos meses se descobriu a síndrome e quais terapias foram realizadas e as atuais atividades realizadas pela criança.

Foi realizada a avaliação da criança de acordo por um examinador treinado de acordo com os itens da Área do Desenvolvimento Motor do Inventário Portage Operacionalizado (IPO). Após a avaliação com os pais da criança, foram realizadas atividades com a criança proporcionando brincadeiras lúdicas com bola, pula corda, corridas, andar de bicicleta, brincar de skate e patine-te, usar uma mesa para a criança escrever letras maiúsculas e minúsculas, recortar figuras, colorir e copiar figuras, usar o apontador com lápis, atividades com papel e movimentos alternados com os dedos.

Após estas atividades realizadas na residência, a criança foi levada a um parque infantil próximo de sua casa (playground), para realizar as seguintes atividades: balançar, 
escorregar no escorregador, andar sobre tábuas, dar saltos e giros, brincar em barras horizontais, com o propósito de avaliar qual foi o desempenho e o comportamento da criança diante destas atividades motoras.

Em todo o momento da atividade a pesquisadora e o responsável pela criança estiveram presentes para garantir o conforto e segurança da criança. Ao final da pesquisa os pais e a criança receberão a devolutiva dos resultados da pesquisa. Por se tratar de um estudo de caso único, os resultados foram tratados em termos descritivos.

\section{Relato de Caso}

Participou da pesquisa uma criança de 8 anos de idade, do sexo masculino, cor branca, cujo diagnóstico e laboratorial de Síndrome de Williams foi realizado com 1 ano e 5 meses.

A criança nasceu com idade gestacional de 40 semanas, o parto foi cesáreo devido à liberação de mecônio durante o trabalhe do parto, sendo que a mãe já apresentava $7 \mathrm{~cm}$ de dilatação, a criança nasceu pesando $2.600 \mathrm{~g}$ e medindo $48 \mathrm{~cm}$ de comprimento a mãe observou que a criança apresentava uma pele mais enrugada, mas depois de algumas horas voltou a normal. Não houve a necessidade de retenção no hospital e nem incubadora, todos os exames necessários e rotineiros após o nascimento foram feitos e não apresentaram nenhuma anormalidade. A criança amamentou do leite materno até um mês e meio e desde cedo apresentava dificuldade de sucção, teve muitas cólicas duradouras que permaneceu até os 5 meses, apresentava todos reflexos esperados. Pelo relato da mãe o desenvolvimento motor da criança era tardio para o esperado comparado dos filhos anteriores.

Aos 6 meses foi observado um estrabismo modero, porém no relato da mãe a criança conseguia acompanhar os objetos. Após os 8 meses iniciou um tratamento com tampão para melhora do estrabismo, sendo que este se mantém até hoje, lembrando que o quadro clínico oftalmológico houve uma reversão estética de $90 \%$.

Iniciou o tratamento fisioterapêutico através do Método Bobath aos 10 meses de idade, salientando que a criança apresentava quadro de hipotonia nos primeiros meses de vida, devido a sua dificuldade de controle cervical e tronco, dificuldades de realizar transferência de prono para supino ou vice-versa, dificuldade de se manter sentado, realizar a transferência do sentar para o engatinha, dificuldades de se arrastar, apanhar e manipular objetos e levar até a boca, sensibilidade tátil, proprioceptiva e déficit de equilíbrio. Permaneceu em tratamento até 2 anos de idade, onde a mãe relata que a criança melhorou seu equilíbrio durante os movimentos, conseguindo realizar transferência do sentar, ajoelhar, semi-ajoelhar e ficar de pé e caminhar, melhorou a coordenação motora de membros superiores e iniciou a educação escolar. Aos 3 de idade conseguia subir escadas, andar de velocípede, correr, arriscava a chutar bolas e brincava com brinquedos de encaixes maiores. Aos 5 anos já conseguia dar chutes direcionados, andava de bicicleta com rodinhas e arriscava o pular, com 6 anos dominou o pula-pula, corria com maior liberdade, maior domínio dos objetos e iniciou as atividades de vida diária como: tomar banho, vestir roupa, se calçar, escovar os dentes, se alimentar e controle esfincteriano, mas realiza as atividades com grande dificuldade e com auxilio de uma pessoa e iniciou a intervenção pedagógica que se encontra até hoje.

Além da fisioterapia a criança recebeu atendimento de fonoaudióloga aos 2 anos de idade e finalizou o tratamento com 7 anos de 6 meses de idade, sendo que mãe relata melhora na pronuncia das palavras, na alimentação e na escrita. Aos 4 anos de idade iniciou tratamento de equoterapia que finalizou com 7 anos de idade, onde teve melhora do controle cervical e postural, melhora de equilíbrio e propriocepção, e diminuição da salivação.

Atualmente, a criança se encontra com 8 anos de idade e está no primeiro ano do ensino fundamental, a mãe relata que na escola apresenta um atraso no desenvolvimento cognitivo, dificuldades na manipulações de números, soluções de problemas, planejamento motor e raciocínio lógico e dificuldades na escrita.

Em relação às atividades de vida diária a criança executa as atividades como: retirar a camisa pela cabeça o calçado sem utilizar as mãos a meia utiliza só polegar e o short utilizando as duas mãos. No banho tem dificuldades para se ensaboar, conseguindo se equilibrar ao lavar os pés perfeitamente, tentando executar os movimentos que the pede. Ao se vestir é necessário que haja um ponto de apoio para se equilibrar, consegui vestir sozinho a camiseta e a 
shorts e ao colocar a meia e o sapato é preciso de auxílio. A criança se alimenta sozinha utilizando uma colher, mas sua preensão é imatura e não utiliza a pinça em tripé e dificuldades na mastigação necessitando de líquido para umedecer os alimentos.

Foi observado que o desenvolvimento motor da criança está de acordo com sua faixa etária, mas apresenta algumas dificuldades para executar movimentos de coordenação motora fina e ampla. Os resultados da avaliação realizada pelo IPO encontram-se apresentados nas tabelas 1 (motricidade fina) e tabela 2 (motricidade ampla).

Tabela 1. Resultados da avaliação da motricidade fina

\begin{tabular}{l|l}
\hline Itens avaliados & Resposta \\
\hline Escrever Letras de imprensa maiúsculas, isoladas e grandes em qualquer lugar do & Realiza \\
papel & \\
Estica os dedos, tocando o polegar em cada um deles & Não realiza \\
Copia letras minúsculas & Não realiza \\
Bate em um prego & Não realiza \\
Consegui colorir sem sair da margem 95\% das vezes & Não realiza \\
Recorta figuras revistas sem sair mais do que 6mm da margem & Não realiza \\
Usa apontador de lápis & Não realiza \\
Copia desenhos complexos & Não realiza \\
Rasga figuras simples de um papel & Não realiza \\
Dobra um papel quadrado duas vezes em diagonal, imitando um adulto & Realiza \\
Apanha um objeto do chão enquanto corre & Não realiza \\
Escreve seu nome com letras de forma em caderno pautado & \\
\hline
\end{tabular}

Tabela 2. Resultados da avaliação da motricidade ampla

\begin{tabular}{l|l}
\hline Itens avaliados & Resposta \\
\hline Anda sobre uma tábua para trás, para frente e para os lados, mantendo o equilíbrio & Não realiza \\
Caminha saltitando & Realiza \\
Balança em um balanço, iniciando e mantendo o movimento & Realiza \\
Sobe em escadas de mão ou na escada de um escorregador de três metros & Realiza \\
Rebate uma bola á medida em que anda com direção & Realiza \\
Apara uma bola leve com uma só mão & Não realiza \\
Pula corda sozinha & Não realiza \\
Golpeia uma bola com um bastão ou pedaço de pau & Realiza \\
Patina uma distância de três metros (ou usa skate) & Não realiza \\
Anda de bicicleta & Realiza \\
Escorrega descendo um monte de areia ou terra & Realiza \\
Anda ou brinca em piscina tendo água até a cintura & Realiza \\
Conduz um patine-te ou carrinho de rolimã dando impulso com só um pé & Realiza \\
Salta e gira em um só pé & Realiza \\
Salta de uma altura de 30cm e aterrisa na planta do pé & Realiza \\
Pára em um só pé, sem apoio, com os olhos fechados, por dez segundos & Não realiza \\
Dependura-se por dez segundos em uma barra horizontal & Não realiza \\
\hline
\end{tabular}

\section{Discussão}

O quadro clínico apresentado pela criança do presente estudo inclui características físicas evidentemente sindrômicas como, fronte larga, fendas palpebrais curtas, abundância de tecido subcutâneo em torno dos olhos, nariz em sela com sulco nasolabial longo e lábios grossos. Existindo problemas cardiovasculares, dificuldades de alimentação, perda ou má oclusão dentária e dificuldades de aprendizado. Estes achados clínicos são compatíveis com as características relatas na pesquisa Machado et al. (1998).
Rossi et al. (2006) afirma que a síndrome decorre da perda de uma das cópias dos genes, localizados na região 7q11.23, associado a problemas cardiovasculares, rostos com características semelhantes,atraso mental moderado, dificuldade para ler, escrever e efetuar operações matemáticas.

A criança selecionada para o estudo deste caso é de sexo masculino com a idade de 8 anos, filho de ambos de pais normais, entrando em conformidade com as descrições de Sugayama (2000). Relata-se que a maioria dos trabalhos da literatura refere-se a SWB como uma doença sem predomínio de sexo ou região geográfica, que na 
maioria das famílias a ocorrência é esporádica,ou seja,ambos os pais são normais.

Observou-se que a criança apresentou uma hipotonia muscular levando ao atraso no desenvolvimento motor, dificultando em seus primeiros passos. Da mesma forma, Gestão et al. (2007) diz que a hipotonia muscular também é muito freqüente, prejudicando o desenvolvimento motor levando a criança a andar somente por volta de 21 meses de idade.

Ao possuir problemas cardíacos e dentários o autor Sugayama et al. (2002) nos mostra que o problema cardíaco ocorre aproximadamente em $80 \%$, sendo a estenose aórtica supra valvular um dos defeitos mais freqüentes, diagnosticado nos dois primeiros anos de vida os dentes da criança são pequenos incluindo raízes pequenas e finas com má oclusão.

No estudo realizado verificou-se que a criança nos primeiros anos de vida apresentava dificuldades importante de alimentação, incluindo vômitos e refluxos, confirmando o estudo de Moreno et al. (1982) e Carrasco et al. (2005), em que a maioria destas crianças tem dificuldades importante de alimentação no primeiro ano de vida, incluindo vomito, recusa de alimentação e refluxo gastresofágico.

A criança do presente estudo faz o uso de tampão ocular e lentes corretivas por apresentar também dificuldades visuais e estrabismo. Segundo Sugayama (2000) a incidência de estrabismo na SWB varia de 29 a $74 \%$ sendo mais freqüentes em lactentes e crianças jovens.

$\mathrm{Na}$ presente pesquisa, observou-se que a criança possui um atraso no aparecimento na pronuncia das palavras, consegue produzir frases com maior fluência, possuindo um vocabulário mais extenso, o que condiz com os estudos de Carrasco et al. (2005) e Sugayama (2001), onde foi conclusivo que a criança com esta síndrome apresenta atraso no aparecimento da linguagem e começa a produzir frases após os três anos de idade e falam com maior fluência possui vocabulário mais extenso e são bons conversadores.

$\mathrm{Na}$ escola a criança possui algumas dificuldades como: ler, escrever, atraso cognitivo, dificuldade de aprendizagem, conceitos matemáticos, temporais e raciocínio lógico. Rossi et al. (2006) mostra em suas pesquisas que o coeficiente de inteligência (QI) varia de 41 a 80, que algumas crianças são mais afetadas que outras, porém a maioria encontra-se na faixa de DM leve e moderado.

Através da aplicação do Inventário Portage observou-se que a criança revelou prejuízo na área do desenvolvimento motor com maior ênfase de dificuldade na motricidade fina em relação a ampla. Sugayama (2000) relata ainda a presença de incoordenação motora e reflexos tendinosos profundos hiperativos presentes, limitação à supinação do antebraço com ou sem sinostose rádio-ulnar e contraturas articulares, podendo afetar nas manipulações de objetos e na escrita.

\section{Conclusão}

Os resultados revelaram que a criança com SWB apresenta maior dificuldade no que se refere às habilidades motoras finas. Com base nos achados do presente estudo, verifica-se que mesmo uma criança sendo portadora desta síndrome rara, poderá ter uma vida normal como qualquer outra criança, necessitando de apoio e adaptações para as suas atividades diárias e escolares.

\section{Referências}

ANTONELL, A., DEL CAMPO, M., FLORES, R., CAMPUZANO, V., PÉREZ, J., Síndrome de Williams: aspectos clínicos y bases moleculares. Revista de Neurologia. 42 suppl. 1, p. 569-575, jan. 2006.

ARAVENA, T. C., CASTILLO, S., CARRASCO, X., MENA, I., LÓPEZ, J., ROJAS, J., SEMBERG, C., SCHROTER, C. G., ABOITIZ, D. Síndrome de Williams: estúdio clínico citogenético, neurofisiológico e neuroanatômico. Revista Médica de Chile, vol.130, n. 6, p. 631-637, Santiago. Jun 2002.

CARRASCO, X., CARTOLLO, S., ARAVENA, T., ROTHHMMER, P., ABOITIZ, F., Williams Syndrome: pediatric and cognitive development. Pediatria Neurologica, p. 72-166, 2005.

EWART, A. K.; MORRIS, C. A.; ATKINSON, D.; JIN, W.; STERNES, K.; SPALLONE, P.; STOCK, A. D.; LEPPERT, M.; KEATING, M. T. Hemizygosity at the elastin locus in a developmental disorder Williams syndrome. Nature Genet, New York, v. 5, n. 1, p. 11-16, 1993.

GESTÃO, M. G., SILVA, J. N. G., LAMÔNICA, D. A. C., DE-VITTO, L. P. M., ABRAMIDES, D. V. M., COSTA, A. R. Evolução das habilidades comunicativas na Síndrome de Williams Processo terapêutico de um caso clínico. Revista 
Sociedade Brasileira de Fonoaudiologia, vol. 19, n. 2, p. 203-211, agosto. 2007.

MACHADO, M. T. et al. Achados NeuroUrológicos da Síndrome de Wiliams: Relato de Caso. Arquivos de Neuro-Psiquiatria, vol.56 n.3B. São Paulo. 1998.

MORENO, R., LACASSIC, Y. Síndrome de Williams: um diagnóstico fenotípico. Revista Chilena Pediatria, vol. 53, n. 2, p. 61-156, 1982.

ROSSI, N. F., FERREIRA, M. D., GIACHETI, M. C. Genética e linguagem na síndrome de Williams-Beuren: uma condição neuro-cognitiva peculiar. Pró-Fono Revista de atualização

Científica, vol.18, n.3, Barueri Sept./Dec. 2006

SUGAYAMA, S. M. M. Uso da análise de Fish para diagnóstico em 11 pacientes com síndrome de Williams-Beuren. Jornal Brasileiro de

Patologia, vol. 36, n. 4, p. 6 -263, out-dez 2000.

SUGAYAMA, S. M. M. Estudo genético-clínico e citogenética molecular pela técnica da hibridação in situ por fluorescência (FISH) em pacientes com síndrome de Williams-Beuren. Tese (Doutorado em Pediatria) - Faculdade de Medicina, Universidade de São Paulo, São Paulo. 2001.

SUGAYAMA, S. M. M., FERREIA, S. C. L., TERADA, K. A., LEONE, C., LOUDES, L. F. A., $\mathrm{KIM}, \mathrm{C}$., Anormalidades oculares em 20 pacientes com Síndrome de Williams-Beuren. Pediatria, São Paulo, vol. 24, n. 3/4, p. 98-104, 2002.

VICARI, S., Memory development and intellectual disabilities. Acta Paediatrica, vol. 93, p. 60-64, 2004.

WILLIAMS, L.C.A.; AIELLO, A.L.R. O Iventário Portage Operazionalizado: Intervenção com Famílias. Editora Memnon, FAPESP, 2001.
Motriz. Revista de Educação Física. UNESP, Rio Claro, SP, Brasil - elSSN: 1980-6574 - está licenciada sob Licenca Creative Commons

\section{Endereço:}

Cibelle Kayenne M. R. Formiga

Rua Mamoré, Quadra F6 Lote 12,

Residencial Araguaia, Alphaville Flamboyant

Goiânia GO Brasil

74883-015

Telefone: (62) 3246.0452 e (62) 8403.3167

e-mail: cibellekayenne@gmail.com 